\title{
REPRODUCTION, FERTILITY AND DEVELOPMENT
}

publish.csiro.au/rd

\section{SCOPE}

Reproduction, Fertility and Development is an international journal for the publication of original and significant contributions to the field of reproductive biology in vertebrate animals, including humans, livestock and wildlife.

Subject areas include, but are not limited to: physiology, biochemistry, cellular and molecular biology, genetics and epigenetics, behaviour, developmental biology, immunology and endocrinology. Our readers are interested in novel developments in reproductive technology, but rarely in clinical science or clinical application of artificial reproductive technology. We are interested in environmental influences on reproduction, including the effects of endocrine disrupting chemicals (EDCs), but rarely publish toxicology or the effects of uncharacterised mixes of chemicals, such as plant extracts, unless the active ingredient is fully defined and the mechanism of action is provided.
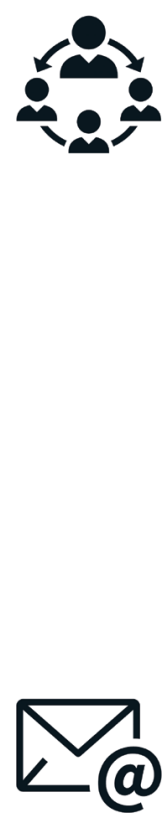

\section{AUTHOR BENEFITS}

- International reach and discoverability

- Indexing in a wide variety of relevant databases, including MEDLINE/PubMed

- Eligible authors receive APC-free Open Access

- Professional copyediting for every paper

- Capture impact through citation tracking and Altmetrics

- Authors retain copyright

- Green Open Access with no embargo

- Gold Open Access compliant with major funders

- No page charges

- Rapid online publication ahead of issue release

\section{STAY IN CONTACT}

- publishing.rfd@csiro.au

- Join the conversation on social media using hashtag \#RepFertilityDev

- Sign up for free journals content emails publish.csiro.au/earlyalert

- Recommend the journal to your librarian publish.csiro.au/journals/recommend

\section{SUBMIT YOUR ARTICLE ONLINE}

- Prepare: publish.csiro.au/rd/forauthors

- Submit: mc.manuscriptcentral.com/csiro-rd

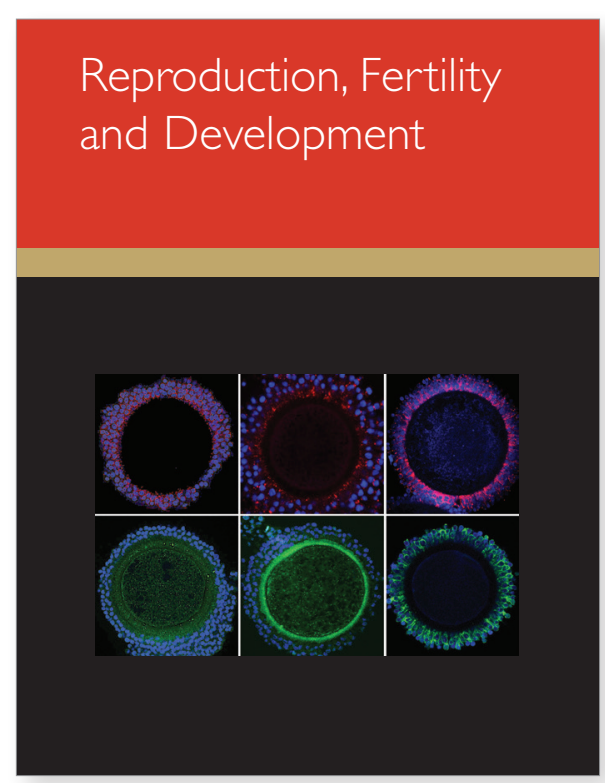

Editors-in-Chief:

Graeme Martin

University of Western Australia

Jenny Juengel

AgResearch, New Zealand

Publishing Model: Hybrid

Open Access options available

Frequency: 18 issues/year

Publishing since: 1989

eISSN: 1448-5990 (online)

Official journal of:

The International Embryo Technology

Society (IETS)

Society for Reproductive Biology (SRB)

C $\mathbf{O} \mathbf{P}$ E

JM12805

As a member of the Committee on

Publication Ethics (COPE), Reproduction,

Fertility and Development supports its

core practices and is committed to

transparency in scholarly publishing.

LEARN MORE ABOUT THE

JOURNAL

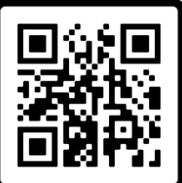

SCAN ME 


\section{JOURNAL METRICS}

\section{SPEED}

38 days from manuscript submission to first decision

$\mathbf{3 7}$ days from manuscript acceptance to publication

\section{USAGE}

243,991 downloads in 2021

$\mathbf{8 2 4}$ Altmetrics mentions in 2021

\section{REJECTION RATE}

$\mathbf{7 4 \%}$ rejection rate in 2021

\section{IMPACT}

Ranking in area

\# 59/176 in Zoology (Q2); 33/39 in Developmental Biology (Q4); 27/31 in Reproductive Biology (Q4)
IF

TC $\mathbf{4 9 0 8}$ Total Citations in 2021

2.1 5-Year Impact Factor
2.0 Impact Factor

JcI 0.8 Journal Citation Indicator

\subsection{CiteScore}

CS Highest percentile 75\% (111/448 Animal Science and Zoology)

0.7 SNIP

Source Normalised Impact per Paper

SJR

$0.5 \mathrm{SJR}$

SCImago Journal Rank
29 h5-index

Google Scholar index for papers published 2017-21

\section{ABOUT CSIRO PUBLISHING}

CSIRO Publishing operates as an editorially independent science publisher within Australia's premier research group, Commonwealth Scientific and Industrial Research Organisation (CSIRO), and has been publishing journals since 1948. Our internationally recognised publishing program includes journals, books and magazines and covers a wide range of scientific disciplines.

\section{PARTNER ORGANISATIONS}

The Association of Society Publishers

Copyright Clearance Center
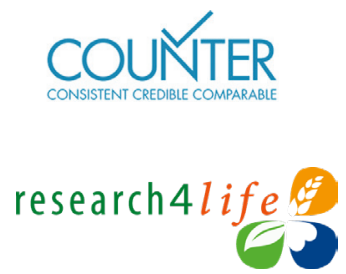

Crossref

Altmetric

$\$$ Dimensions

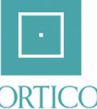

\section{publons}

